\title{
Spectrum of paediatric orthopaedic injuries in Patient attending emergency department of Gandaki Medical College of Pokhara, Nepal
}

\section{Ishwor Sharma Kandel ${ }^{1}$, Karuna Acharya ${ }^{2}$, Sandip Gupta ${ }^{3}$, Bhola Shrestha ${ }^{1}$ Authors Affiliations}

${ }^{1}$ Associate Professor, Department of Orthopaedic and Trauma surgery, Gandaki Medical college and Teaching Hospital (GMCTH), Pokhara, Nepal

${ }^{2}$ Associate Professor, Department of General Practices and Emergency Medicine, GMCTH

${ }^{3}$ Assitant professor, Department of General Practices and Emergency Medicine, GMCTH

\section{Correspodence :}

Dr. Ishwar Sharma Kandel,

Associate Professor,

Department of Orthopaedic and Trauma surgery, Gandaki Medical college and Teaching Hospital ( GMCTH), Pokhara, Nepal

E-mail:drisk79@gmail.com

Article recived : 5th Oct. 2018

Article accepted : 8th jan. 2018

\section{ABSTRACT}

Background: Children are vulnerable to musculoskeletal injuries both at home and on the street for various reasons. Morbidity and disabilities resulting from these, mostly preventable, injuries, make them a burden to their families and society. The role of various factors associated with injuries is often not documented.

Methods: This prospective, cross sectional study was done on 80 children aged below 16 years with musculoskeletal trauma, data were collected and analysis was done using Microsoft excel and frequency table. The various modes of injuries, place of injuries, pattern of injuries and regional distribution of injuries were analyzed.

Results: One in every four to five patient was a child below 16 years of age. Boys were injured more than girls. Injuries, especially fractures, were most common in the extremities, the upper limb more commonly injured than the lower limb. Most of the injuries occurred at home. The most common mode of injuries was falls that happened while playing both within and outside the home, followed by road traffic accidents. Most injuries occurred during daytime.

Conclusions: Many injuries in children were found to be preventable. Small interventions and modification while constructing homes and surroundings can contribute tremendously to injury prevention and control in children. Parental awareness about the various modes of injury, role of supervised playing and their responsibility towards injury prevention can play a key role in reducing the morbidity associated with childhood fractures.

Key Words: Children, Fracture, Injuries, Orthopaedics, Spectrum

\section{INTRODUCTION}

Musculoskeletal injuries in all age group due to fall from height or road traffic accidents are common orthopaedic problem for the visit of hospital in countries like Nepal. These injuries have immediate and long term negative impact in the socioeconomic and health status of the countries. ${ }^{1}$ Accurate data on the incidence of musculoskeletal injuries and their impact in society is lacking in many countries. In comparison to adults children are most vulnerable to injuries both at home and on the street for a variety of reasons. These include living in an environment where the basic infrastructure is adapted for adults. Besides, children have a limited development of their own risk perception ability and behavior apart from their inherent physical vulnerability. ${ }^{1}$

Children can get injuries in different forms and ways. Many of these injuries may not be reported. Injuries may vary according to age and gender. Rate of injuries 6 is influenced by subtle variation of cultural lifestyle and 
behavioral patterns e.g. play behavior of children, design and layout of homes and play area. Accidents, do not just happen, they are caused. The traditional view of injury as an accident has resulted in the neglect of this aspect of public health. Today injuries are low in priority for policy makers and only few plans are drawn for injury prevention. It is an irony that thousands of children saved from nutritional and infectious diseases are killed or maimed by injuries. ${ }^{2}$ The fatalistic attitude that accidents are inevitable needs to be curbed. Prevention of childhood injuries is of great importance to both individuals and society but unfortunately, has largely been either excluded from attention or treated in an inappropriate manner. ${ }^{3}$ Patients may survive their primary injuries only to become chronically disabled and become a burden to their families and the society. The causes and pattern of injuries may vary in different geographical region, socioeconomic status, living standard and play habit of children. The objective of this study was to find the Mode of injury, different pattern of soft tissue injury and bony injuries and their regional distribution so that health policies can be made to minimize such injuries in different region of country.

\section{MATERIALS AND METHODS}

This is a cross sectional observational study conducted in Gandaki Medical College, Pokhara, Nepal for the period of two months; June and July 2017 AD. In total 2460 patient attended in emergency department in two months, 476 were of orthopedic related injury and among that 106 were paediatric musculoskeletal injury. Eighty paediatric patients who met inclusion criteria were included in this study out of 106 paediatric musculoskeletal injury. Any children below 16 years of age with musculoskeletal injury presented within 48 hour of incident in emergency were included. Children with associated major neurosurgical, chest or abdominal injury were excluded from the study.

The data of various modes of injuries, place of injuries, pattern of injuries and regional distribution of injuries were collected and analysis was done using Microsoft excel and frequency table. Patient's demographic profile including age, sex, side, site and timing of injury were recorded.

\section{RESULTS}

There were 80 patients in total with age range from one to fifteen and average was nine years.
The results of the study are shown in following tables. Demographic profile of injury is depicted in the tables 1, Mode of injury in Table 2, Regional distribution of skeletal injury in table 3 and Regional distribution of soft tissue injury in table 4.

Table 1. Demographic profile of injury

$\begin{array}{lcc}\text { Age Wise distribution } & 1-5 & 14 \\ & 6-10 & 34 \\ & 11-15 & 32 \\ \text { Sex } & \text { Male: Female } & 56: 24 \\ \text { Side of injury } & \text { Left: Right } & 8: 36 \text { ( } 6 \text { spine injury) } \\ \text { Type of injury } & \text { Skeletal:Soft tissue } & 64: 16 \\ \text { Time of injury } & \text { Day time: Dark } & 57: 23 \\ \text { Place of Injury } & \text { House: Outside } & 44: 36\end{array}$

Table 2. Mode of Injury

1 Fall 63

Fall from roof (8)

Roof with parapet (1)

Roof without parapet (7)

Fall from Stair (14)

With railing (11)

Without railing(3)

Fall from bed (5)

Fall while playing(28)

Running(9)

Sea-saw(4)

Cycling(5)

Football(6)

Kabaddi(4)

Fall from Tree(8)

2 Road Traffic Accidents 7

$3 \quad$ Hit by football 4

$4 \quad$ Hit by volleyball 2

5 Domestic/ Hit by teacher 4

violent injury in school(2)

Pulled by elder brother in

elbow(1)

Stepped by adult while sleeping

in floor(1)

Total

80

Radiograph of supracondylar fracture of humerus (Figure1) and fracture shaft of femur ( Figure 2)in children.

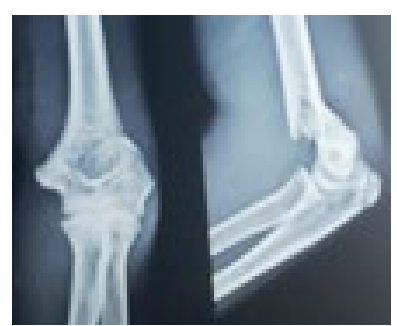

Figure1. supracondylar fracture of humerus 


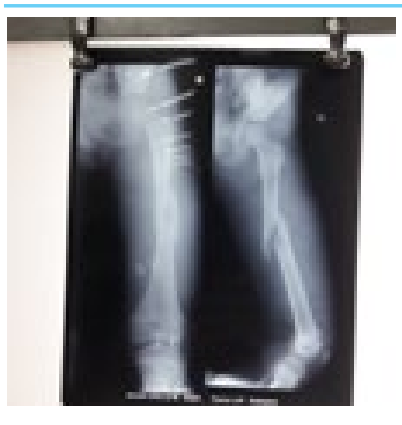

Figure 2. Fracture shaft of femur

Table 3. Regional distribution of Skeletal injury

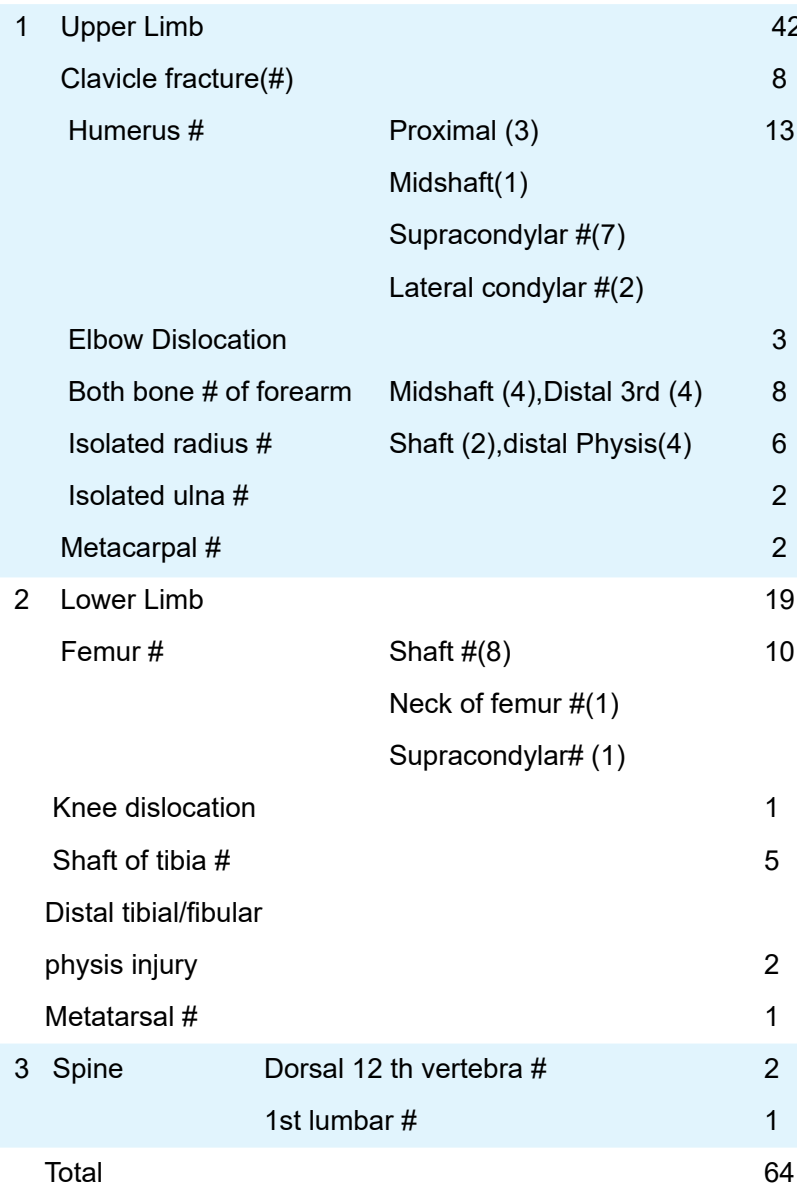

Table 4. Regional Distribution of soft tissue injury

$\begin{array}{lll}1 \quad \text { Upper limb(8) } & \\ \text { Shoulder and arm } & 1 \\ \text { Elbow } & 4 \\ \quad \text { Forearm and wrist } & 3 \\ \quad \text { Lower Limb(5) } & \\ \text { Hip and Thigh } & 2 \\ \text { Knee } & 1 \\ \text { Ankle and foot } & 2 \\ \text { Spine(3) } & \\ \text { Thoracic } & 2 \\ \text { Lumbar } & 1 \\ \text { Total } & 16\end{array}$

\section{DISCUSSION}

In this study out of 476 orthopaedic related injury 80 were children below 16 years of age that means almost one in every six injured patient was a child below 16 years. Among the children the most common age group was between 6 and 10 years, constituting $42.5 \%$ of the musculoskeletal injuries. ${ }^{1,3}$ Adolescent children are usually active and playful without the maturity of being careful hence most of childhood injuries are seen in this age group. In our study boys were found to be injured more commonly than girls, similar to the reports in the literature. ${ }^{1,4-9}$ The male: female ratio in our series was found to be 2.3:1 which is only slightly different from the ratios of $2: 19$ and 2.2:14 This is because boys are by nature more active and girls indulge more in sedentary games.

In our study injuries were found to be more common during the daytime $(72 \%)$ than in the dark $(28 \%)$. This is probably due to the fact that children are awake and more active during daytime. There is a lacuna in the literature regarding this finding. 1 In our study more than half of the injuries $(55 \%)$ occurred at home. Injuries at home have been reported to be quite common but constitute only about one third of injuries. ${ }^{1,10}$ Parents often leave their children alone and unattended at home thinking that they would be safe. Also parents tend to be casual when children are playing in the house even if they are present. Since the parents cannot keep a constant vigil on the children, injuries at home may be more common than expected. The modes of injury of most of the children depict that carelessness is a common factor even at home, depicted by the fact that many children are injured by fall from stairs at Home.

Various mode of injury have been found to be associated with injuries in children, but the commonest mode of injury was fall $(63 / 80)$. This was similar to the reports of other studies $1,3,4,9,11$ but different from one study, 10 according to which road traffic accident (RTA) was the most common mode. In our study the second most common cause of injury was RTA (7/80). Most of the falls occurred while playing (28/63). The various activities during playing included running (9/28), football (6/28), cycling (5/28), sea-saw (4/28), kabaddi (4/28). Second most common cause of falls were slipping from stairs (14/63). In most of these cases, children tumbled on the stairs while climbing or running down.In three cases the railings were not present and in all these three cases the children fell 
from the side of the stairs on to the floor.

Another mode of fall was from roof (8/63) most commonly from the first story of house similar to other studies.9 In most of these cases (7/8) the boundary wall was either not present or too low (less than 1 foot) to be effective against falls. In one patient where the boundary wall was present, the child fell over the wall. Most of the falls from roof occurred while playing (5/8), unsupervised kite flying (2/8) and during a casual walk (1/8). Five children were injured due to unsupervised fall from bed. Eight children fell from fruit trees while picking fruits, this finding is in agreement with other studies. . $2,12^{2}$

The road traffic accidents were responsible for seven injuries. Two of these occurred on busy roads when the entire family, of three members, was on a two-wheeler (motorbike). In one case, the child was sitting in the front over the tank of a motorbike while in other the child in the lap of the mother who was sitting with both legs on the same side on the rear seat of the scooter. Three accidents occurred on not so busy roads while children were crossing roads unsupervised and got hit by a scooter in two and a bicycle in one. One accident occurred when the child jumped off a running jeep. One accident was a cycle spoke injury when the child was sitting on the back of an adult size bicycle driven by an adult. six of the eighty children were injured after being accidentally hit with football in four and volley ball in two while playing. Injuries resulting from violence like hit by teacher at school were found in two children, one girl was injured after being stepped over by an adult while sleeping on the floor and one child was injured after being carelessly pulled and picked up by one arm by elder brother.

Out of the eighty children, sixty four had skeletal injuries and sixteen had soft tissue injury Fiftyeight of the sixty-four fractures (90.6\%) were closed fractures while the remaining six were (9.37\%) were open, similar to the study by Lyons et al.10Upper limb injuries $(62.5 \%)$ were more common than the lower limb injuries (30\%) and in confirmation to the reports of other studies $1,4,7$ followed by spine $(7.5 \%)$.The common fractures in children were found to be fracture of shaft of femur (14.06\%), followed by fracture of both bones of forearm (12.5\%), fracture of clavicle $(12.5 \%)$ and supracondylar fracture of humerus (10.9\%). This result differs from other studies 4,10 according to which supracondylar fracture of humerus was the second most common fracture in children after fracture shaft femur and not fracture both bone forearm or clavicle fracture as in this study.

Fracture of both bones of forearm(8) and clavicle(8) fracture were the most common fracture of the upper limb followed by supracondylar fracture of the humerus in seven cases. Fracture shaft femur was the most common fracture in children (14.06\%) among all injures and not only among the fractures of the lower limb. This finding is similar to other studies.1,4,8 The second most common fracture of lower limb was fracture shaft tibia (5/19). About one fourth of the children referred to orthopaedics had soft tissue injuries (25\%). The sites of these injuries covered almost the whole body including spine, upper limb and lower limb. Children are susceptible to soft tissue injuries on any part of the body depending on the mechanism of injuries. Minor abrasions and superficial bruises and skin wounds treated by the casualty staff and not referred to the orthopedics department were excluded in the study.

\section{CONCLUSION}

Medical college hospital based study of Gandaki Province of Nepal showed that one in every four to five patient sustaining musculoskeletal injuries was a child below 16 years of age. Boys were affected more often than girls in all age groups of children and most of the injuries were seen in the age group of 6 to 10 years. Home, which was considered safe, was the most common place where children are injured.. Skeletal injuries constituted $80 \%$ of all the injuries in the children and the upper limb was twice more commonly injured than the lower limb. The most common fracture was that of the shaft of femur followed by fracture of both bones forearm, fracture of clavicle and supracondylar fracture of the humerus. There were various modes of injury in children, the most common being fall during playing. Injuries in children were found to be preventable. Small interventions while constructing homes like mandatory boundary wall on the roof, railings on stairs, keeping iron objects away from the site of playing can contribute tremendously to injury prevention and control in children. Parental awareness about the various modes of injury, role of supervised playing and their responsibility towards injury prevention can play a key role in reducing the morbidity associated with childhood fractures. Health education to parents, teachers, official of government 
Orginal Article Medical Journal of Pokhara Academy of Health Sciences (MJPAHS) Vol. 1 Issue 2 Jul-Dec 2018

and non-government stake holders, building

contractors and construction site workers will certainly help to prevent or reduce the play ground and fall injuries.

\section{Acknowledgement}

We would like to express heartfelt thanks to all emergency department and orthopedics ward staff of GMCTH for help to gather data.
Conflict of Interest

We declare that we have no competing interest and have not received any funding or benefit to conduct the study.

\section{REFERENCES}

1. Sural S, Verma A. The clinical profile of musculoskeletal injuries in children attending a major hospital in Delhi, India,Journal of clinical Orthopaedic and Trauma.2015;6:12-18

2 W.H.O. Injuries in South-East Asia region, Priorities for policy and action. SEA. Injuries. 2002:A1.

$3 \quad$ Sehgal A, Jain S, Jyothi MC. Parental awareness regarding childhood injuries. Indian J Pediatr. 2004;71:125e128.

$4 \quad$ Bandi SK, Agarwal SN. Analytic study of trauma pattern in pediatric age group in Indore region. Indian Pediatr.1980;17:434e437.

5 Demore DT, Metzl JD, Ramundo M, Pan S, Van AR. Patterns in childhood sports injury. Pediatr Emer Care. 2003;19:65e67.

$6 \quad$ Hinton RY, Licoln A, Crockett MM, Sponseller P, Smith G.Fractures of the femoral shaft in children. Incidence, mechanisms \& sociodemographic risk factors. The John Hopkins School Of Hygiene \& Public Health, Baltimore,Maryland 21205, U.S.A J Bone Joint Surg Am. 1999;81:500e509.

7 Kelon J, Ahlhelm F, Anagnostakos K, et al. Gender-specific differences in school sports injuries. Sport verletz Sportschaden. 2004;18:179e184.

$8 \quad$ Nwadinigwe CU, Ihezie CO, lyidiobi EC. Fractures in children. Niger J Med. 2006;15:81e84.

9 Sharma AK, Sarin YK, Manoch S, Agarwal LD, Shukla AK, Zaffar M. Pattern of childhood trauma: Indian Perspective. Indian J Pediatr. 1993;30:57e60.

Lyons RA, Sander V, Weightman AL, et al. Modification of home environment for the reduction of injuries. Cochrane Database Syst Rev. 2003:CD003600.

11 Mittal BN. Epidemiological trial in domestic accidents. Indian J Med Res. 1975;63:9.

12 Mohan D. Childhood injuries in India: extent of the problem and strategies for control. Indian J Pediatr. 1986;53:607e615. 